\title{
Importance of Laplacian of Low-Level Warming for the Response of Precipitation to Climate Change over Tropical Oceans ${ }^{\mathscr{O}}$
}

\author{
Margaret L. Duffy and Paul A. O'Gorman \\ Department of Earth, Atmospheric, and Planetary Sciences, Massachusetts Institute of Technology, \\ Cambridge, Massachusetts \\ LARISSA E. BACK \\ Department of Oceanic and Atmospheric Sciences, University of Wisconsin-Madison, Madison, Wisconsin
}

(Manuscript received 20 May 2019, in final form 31 January 2020)

\begin{abstract}
Several physical mechanisms have been proposed for projected changes in mean precipitation in the tropics under climate warming. In particular, the "wet-get-wetter" mechanism describes an amplification of the pattern of precipitation in a moister atmosphere, and the "warmer-get-wetter" mechanism describes enhanced upward motion and precipitation in regions where the increase in SST exceeds the tropical-mean increase. Studies of the current climate have shown that surface convergence over the tropical oceans is largely driven by horizontal gradients of low-level temperature, but the influence of these gradients on the precipitation response under climate warming has received little attention. Here, a simple model is applied to give a decomposition of changes in precipitation over tropical oceans in twenty-first-century climate model projections. The wet-get-wetter mechanism and changes in surface convergence are found to be of widespread importance, whereas the warmer-get-wetter mechanism is primarily limited to negative anomalies in the tropical southern Pacific. Furthermore, surface convergence is linked to gradients of boundary layer temperature using an atmospheric mixed layer model. Changes in surface convergence are found to be strongly related to changes in the Laplacian of boundary layer virtual temperature, and, to a lesser extent, the Laplacian of SST. Taken together, these results suggest that a "Laplacian-of-warming" mechanism is of comparable importance to wet get wetter and warmer get wetter for the response of precipitation to climate change over tropical oceans.
\end{abstract}

\section{Introduction}

Large changes in tropical precipitation are projected to occur with climate change (Collins et al. 2013), but there are substantial differences between GCMs in the pattern of these changes (Neelin et al. 2006; Kent et al. 2015; Chadwick et al. 2016). Furthermore, the robustness of the response shows little improvement from CMIP3 to CMIP5 (Knutti and Sedláček 2013). To better understand the response of precipitation in different models, it is useful to distinguish the contribution to the precipitation response from changes in temperature or

Supplemental information related to this paper is available at the Journals Online website: https://doi.org/10.1175/JCLI-D-190365.s1.

Corresponding author: Margaret L. Duffy, mlduffy@mit.edu humidity (the thermodynamic contribution) and the contribution related to changes in winds or convective mass fluxes (the dynamic contribution). Such a decomposition can be based on the water vapor budget (e.g., Held and Soden 2006; Seager et al. 2010), an approximate relation involving convective mass flux and lowlevel specific humidity (e.g., Chadwick et al. 2013), or the dry static energy (DSE) budget (e.g., Muller and O'Gorman 2011).

The thermodynamic contribution to changes in precipitation results in an amplification of the historical pattern of precipitation (or precipitation minus evaporation) due to increases in water vapor content of the atmosphere with warming. This amplification was referred to as the "direct moisture effect" by Chou and Neelin (2004) and as wet regions getting wetter and dry regions drier by Held and Soden (2006); we will refer to it as the "wet-get-wetter" mechanism for brevity. Wet 
get wetter becomes evident in the global-scale pattern of precipitation change over ocean in climate model projections (Held and Soden 2006; Byrne and O'Gorman 2015), but it is strongly modified by the dynamic contribution at regional scales over tropical oceans (Chou et al. 2009; Xie et al. 2010; Chadwick et al. 2013).

The dynamic contribution to changes in precipitation is a major source of uncertainties in the projected precipitation response in the tropics (Kent et al. 2015). Chou and Neelin (2004) used the moist static energy (MSE) budget to illustrate how a dynamic contribution can arise through decreases in convective instability at convective margins (the "upped ante" mechanism) and through changes in gross moist stability in convective regions. Changes in gross moist stability have also been used to argue for a "warmer-get-wetter" mechanism that leads to a positive dynamic contribution to precipitation change in regions where SST increases by more than the tropical mean (Xie et al. 2010; Ma and Xie 2013; Huang et al. 2013; Huang 2014). ${ }^{1}$ According to this mechanism, a greater increase in SST in a certain region leads to a local decrease in gross moist stability, which favors more ascent and precipitation in that region. The influence of the pattern of SST change is found to be surprisingly large compared to wet get wetter over tropical oceans, and this has been argued to be because wet get wetter is largely offset by a weakening of convective mass fluxes (Chadwick et al. 2013).

The mechanisms discussed above for the dynamic contribution to the precipitation response to climate change are based on changes in stability of the atmospheric column. But it is well known for the present climate that SST gradients drive boundary layer pressure gradients that strongly affect patterns of surface convergence (SC) and precipitation over tropical oceans (Lindzen and Nigam 1987; Battisti et al. 1999; Sobel 2007; Back and Bretherton 2009a). In addition, the mechanisms discussed above effectively assume a single mode (e.g., a first baroclinic mode) of vertical motion, but observations and reanalysis show that the shape of vertical motion varies strongly across precipitating regions of the tropical oceans (e.g., Trenberth et al. 2000; Back and Bretherton 2006; Back et al. 2017). For example, vertical motion in the west Pacific warm pool is typically "top heavy" while vertical motion in the east Pacific ITCZ is typically "bottom heavy" (Back et al. 2017).

Motivated by the need for two modes of vertical motion and the importance of boundary layer dynamics

\footnotetext{
${ }^{1}$ Changes in SST are linked to changes in vertical velocity with climate change, so warmer get wetter can be considered a dynamic mechanism.
}

for precipitation, Back and Bretherton (2009b, hereafter BB09b) introduced a simple "two-mode" model for precipitation over tropical oceans in the current climate [see also the model of Sobel and Neelin (2006), which shares some similar features]. The two-mode model uses the DSE budget to relate precipitation to radiative cooling, DSE stratification, and vertical motion. Vertical motion is represented by a combination of deep and shallow modes. The deep mode is tied to SST through an empirical convective instability argument. ${ }^{2}$ The shallow mode is tied to SC, which is strongly related to gradients of SST, as shown by Lindzen and Nigam (1987) and Back and Bretherton (2009a, hereafter BB09a). Thus, the two-mode model brings together into one framework many factors that are thought to affect precipitation: radiative cooling (in the DSE budget), mean temperature (which affects the DSE stratification), and column moist stability and SC driven by SST gradients (through the shallow and deep modes).

Here, we adapt and apply the two-mode model of BB09b to better understand the response of precipitation over tropical oceans to climate change in CMIP5 simulations (Taylor et al. 2012). Based on the two-mode model, we are able to quantify the relative contributions of wet get wetter, warmer get wetter, and changes in SC for the precipitation response. Changes in SC are found to be of widespread importance, and so we further investigate them using the atmospheric mixed layer model (MLM) of Stevens et al. (2002) and BB09a. The changes in SC are found to be strongly related to changes in the Laplacian of low-level temperatures, suggesting that a previously overlooked "Laplacian-of-warming" mechanism is important for projected precipitation changes. A limitation of our approach is that changes in SST (or boundary layer temperature) are taken as given whereas they are actually part of the coupled atmosphere-ocean response. For example, in a simple model, cloud-shading effects tend to dampen high SST, weakening SST gradients (Peters and Bretherton 2005; Bretherton and Hartmann 2009). Further, Naumann et al. (2019) used a simple model to show that shallow circulations can be driven by differential radiative cooling in addition to the influence of the SST gradients emphasized here. Nonetheless it is useful to understand how changes in precipitation are influenced by changes in SST.

We begin by describing the two-mode model of BB09b (section 2), and we then apply it to climate projections of precipitation in CMIP5 models to evaluate the relative contributions of wet get wetter, warmer get

\footnotetext{
${ }^{2}$ Unlike in Sobel and Neelin (2006), the deep mode could not be constrained by the MSE budget because its effective gross moist stability was close to zero.
} 
wetter, and changes in SC (section 3). We use the MLM to relate the changes in SC to changes in low-level temperatures (section 4), and we combine the two-mode model with approximations for SC to evaluate the role of changes in the $\nabla^{2}$ SST for the precipitation response (section 5). We further assess our interpretation of the mechanisms for changes in precipitation using atmosphere-only simulations forced by prescribed SSTs (AMIP simulations) that isolate the effect of the pattern of changes in SST (section 6) before giving our conclusions (section 7).

\section{Two-mode model for tropical precipitation}

We use a two-mode model of monthly-mean precipitation that is similar to the model derived in BB09b but with some improvements. The model's characteristic approximation is the decomposition of the vertical profile of vertical velocity into its two leading modes of variability. Differences from the $\mathrm{BB} 09 \mathrm{~b}$ version of the two-mode model are described in the appendix.

The derivation of the two-mode model begins with the time-mean column-integrated DSE budget. Following BB09b, we neglect horizontal advection of DSE, eddy DSE fluxes, and surface sensible heat fluxes over tropical oceans so that the DSE budget is approximated by its dominant terms which relate to latent heating, vertical advection of DSE, and the radiative flux convergence:

$$
L P \simeq\left\langle\omega \frac{\partial s}{\partial p}\right\rangle-R
$$

Here, $P$ is the time-mean surface precipitation rate, $L$ is the latent heat of condensation neglecting fusion, \langle\rangle is a mass-weighted vertical integral over a tropospheric column, $\omega$ is the time-mean vertical velocity in pressure coordinates, $s$ is the time-mean DSE, and $R$ is the timemean radiative flux convergence. The tropospheric vertical integral is taken between a nominal tropopause at $100 \mathrm{hPa}$ and surface at $1000 \mathrm{hPa}$, but due to data availability the radiative flux convergence, $R$, is defined as the net longwave and shortwave fluxes at the surface minus the top-of-atmosphere (TOA), with radiative fluxes defined positive when upward. In this section, the two-mode model is evaluated using observations and reanalysis, but in later sections it is applied to climate model output. All data are monthly and are first averaged over years to give 12 climatological values at a given location.

\section{a. The two-mode approximation}

The vertical velocity as a function of pressure is approximated using its two dominant modes of horizontal and temporal (seasonal) variability as calculated using EOF analysis. The EOF analysis is applied to the climatological monthly $\omega$ between 100 and $1000 \mathrm{hPa}$ using all grid points over the tropical oceans $\left(20^{\circ} \mathrm{S}\right.$ to $\left.20^{\circ} \mathrm{N}\right)$ and including the seasonal cycle. Linear combinations of the two leading EOFs are used to define shallow and deep modes. Without loss of generality, the linear combination for the deep mode is chosen by requiring the deep mode to have zero SC, and the shallow mode is then defined to be orthogonal to the deep mode. This choice of linear combinations allows us to directly relate the shallow-mode amplitude to SC using mass continuity. We approximately impose zero SC in the deep mode by requiring $\omega$ to be equal at the two lowest pressure levels (see appendix). The shallow mode has structure $\Omega_{s}(p)$ and amplitude $o_{s}(x, y, t)$, and the deep mode has structure $\Omega_{d}(p)$ and amplitude $o_{d}(x, y, t)$. The two-mode approximation is written as

$$
\omega(x, y, t, p) \simeq o_{s}(x, y, t) \Omega_{s}(p)+o_{d}(x, y, t) \Omega_{d}(p) .
$$

The vertical advection of the DSE term, $\langle\omega(\partial s / \partial p)\rangle$, is then written $M_{\mathrm{ss}} O_{s}+M_{\mathrm{sd}} O_{d}$, where $M_{\mathrm{ss}}=\left\langle\Omega_{s}(\partial s / \partial p)\right\rangle$ is the gross dry stratification of the shallow mode, and $M_{\text {sd }}=\left\langle\Omega_{d}(\partial s / \partial p)\right\rangle$ is the gross dry stratification of the deep mode.

We use multiple linear regression to approximate the radiative flux convergence, $R$, as a linear function of the two mode amplitudes,

$$
R(x, y, t) \simeq R_{0}+r_{s} o_{s}(x, y, t)+r_{d} o_{d}(x, y, t),
$$

where $R_{0}, r_{s}$, and $r_{d}$ are constant regression coefficients. We interpret $R_{0}$ to correspond to spatially averaged radiative heating, while $r_{s}$ and $r_{d}$ approximately account for the spatially varying interaction of radiation with clouds and water vapor. Using these radiation regression coefficients, we define gross dry effective stratifications as $M_{\mathrm{ses}}=M_{\mathrm{ss}}-r_{s}$ and $M_{\mathrm{sed}}=M_{\mathrm{sd}}-r_{d}$. Following BB09b, we replace $M_{\text {ses }}$ and $M_{\text {sed }}$ by their horizontal and temporal averages over the tropical oceans such that they are constants (although they do differ between climates and GCMs in the analysis that follows). Using constant $M_{\text {ses }}$ and $M_{\text {sed }}$ is a good approximation because horizontal temperature gradients are weak over tropical oceans. Combining the simplified DSE budget [Eq. (1)], the two-mode approximation [Eq. (2)], and the radiative flux convergence approximation [Eq. (3)] gives

$$
L P(x, y, t) \simeq M_{\mathrm{ses}} o_{s}(x, y, t)+M_{\mathrm{sed}} o_{d}(x, y, t)-R_{0} .
$$

\section{b. Relating the mode amplitudes to surface quantities}

The mode amplitudes ( $o_{s}$ and $o_{d}$ ) are then related to surface quantities, namely relative SST and SC. Relative 
SST, denoted $\mathrm{SST}_{\text {rel }}$, is calculated as SST minus SST averaged over the tropical oceans for a given month. SC is calculated using monthly-mean near-surface $(10 \mathrm{~m})$ winds. Throughout the paper, horizontal derivatives and the divergence operator are calculated in spherical coordinates using one-sided differences at the coasts and centered finite differences elsewhere.

The continuity equation is used to relate the shallowmode amplitude $o_{s}$ to $\mathrm{SC}$ as

$$
o_{s}(x, y, t)=a_{s} \operatorname{SC}(x, y, t) .
$$

Applying the two-mode approximation for $\omega$ [Eq. (2)] to the continuity equation at the surface, $\mathrm{SC}=\partial \omega / \partial p$, gives that $\mathrm{SC}=\left(d \Omega_{s} / d p\right)_{\text {surface }} O_{s}$, where we have used that the deep mode is defined to have zero SC. It follows that the coefficient $a_{s}$ is given by $\left(d \Omega_{s} / d p\right)_{\text {surface }}^{-1}$ which we evaluate using $\Omega_{s}$ at the two pressure levels that are nearest the surface.

The deep-mode amplitude $o_{d}$ is approximated by a multiple linear regression with $\mathrm{SST}_{\text {rel }}$ and $\mathrm{SC}$,

$$
o_{d} \simeq b_{\mathrm{SST}} \mathrm{SST}_{\text {rel }}+b_{\mathrm{SC}} \mathrm{SC}+b_{0},
$$

where $b_{\mathrm{SST}}, b_{\mathrm{SC}}$, and $b_{0}$ are regression coefficients. The regression coefficients are calculated using locations and months for which climatological $\mathrm{SST}_{\text {rel }}$ is positive because we want to broadly focus on precipitating regions but the resulting estimate of $o_{d}$ is relatively insensitive to this choice. By including SC in the deep-mode regression we are effectively including the shallow-mode amplitude to account for the favorable effect of shallow ascent and moistening of the environment for deep convection. As discussed in detail in the appendix, BB09b used a different deep-mode approximation, but we find that the approximation given by Eq. (6) is more consistent with the relationship inferred from reanalysis and observations.

\section{c. Expression for precipitation and comparison to observations}

An expression for precipitation comes from combining Eq. (4) with Eqs. (5) and (6), but this can give negative precipitation because of the approximations used [e.g., Eq. (6) is not accurate for negative $\mathrm{SST}_{\text {rel }}$. Therefore, we include a Heaviside function, $H()$, to prevent the approximations from giving negative precipitation. The final model for precipitation over tropical oceans, referred to the two-mode model, is given by

$$
\begin{aligned}
L P \simeq & H(\chi) \chi, \\
\chi(x, y, t)= & M_{\mathrm{ses}} a_{s} \mathrm{SC}(x, y, t)+M_{\mathrm{sed}}\left[b_{\mathrm{SST}} \operatorname{SST}_{\mathrm{rel}}(x, y, t)\right. \\
& \left.+b_{\mathrm{SC}} \mathrm{SC}(x, y, t)+b_{0}\right]-R_{0} .
\end{aligned}
$$

Notice that SC and $\mathrm{SST}_{\text {rel }}$ are the only spatially varying inputs. The parameters $M_{\mathrm{ses}}, a_{s}, M_{\mathrm{sed}}, b_{\mathrm{SST}}, b_{\mathrm{SC}}, b_{0}$, and $R_{0}$ are constants in our evaluation based on reanalysis data, and they only vary between climates and GCMs in our climate-model analyses. The coefficient $a_{s}$ relates the shallow-mode amplitude to SC; $M_{\text {ses }}$ and $M_{\text {sed }}$ combine the dry stratification of the atmosphere with the shallowand deep-mode structures, respectively; and $b_{\mathrm{SST}}, b_{\mathrm{SC}}$, and $b_{0}$ are empirical linear regression coefficients relating the deep-mode amplitude to $\mathrm{SST}_{\text {rel }}$ and SC.

We evaluate the two-mode model over August 1999 through July 2009 using monthly ERA-Interim reanalysis data (Dee et al. 2011) for vertical velocity, temperature, geopotential, and shortwave and longwave radiative fluxes at the surface and top of atmosphere; monthly QuikSCAT observational data for winds used to calculate SC (NASA 2012a,b); and monthly NOAA optimal interpolation SSTs (Reynolds et al. 2002). The time period was chosen based on availability of QuikSCAT data. Here and throughout the paper, all data are linearly interpolated to a $1^{\circ} \times 1^{\circ}$ horizontal grid and an evenly spaced pressure grid. Grid boxes with nonzero land are masked based on the land fraction variable from the GFDL-CM3 GCM, and the same land mask is used throughout. The deep mode has ascent throughout the troposphere with the strongest ascent in the upper troposphere, while the shallow mode has ascent only in the lower troposphere and weak descent in the upper troposphere (Fig. A1a).

We first compare spatially smoothed time-mean precipitation from the two-mode model to GPCP (Adler et al. 2003) over August 1999 through July 2009 (Fig. 1). Throughout the paper, where spatial smoothing is indicated it is done by convolving the data with a twodimensional, nine-point averaging filter. Also throughout the paper, precipitation from the two-mode model is evaluated using as inputs climatological monthly-mean $\mathrm{SC}$ and $\mathrm{SST}_{\text {rel }}$ averaged over all years for each month of the year. As compared to monthly-mean GPCP (Fig. 1a), the two-mode model accurately captures the distribution of monthly-mean precipitation (Fig. 1b) with a RMSE of $2.08 \mathrm{~mm} \mathrm{day}^{-1}$. The original two-mode model from BB09b (Fig. 1c) gives a similar distribution of precipitation, but it has a higher RMSE of $2.30 \mathrm{~mm} \mathrm{day}^{-1}$. The seasonal cycle is included in the RMSE values that we report, but the RMSE of the annual mean is actually higher for the new version of the model than the BB09b version of the model. The most important difference between the new and BB09b versions of the two-mode model is the deep-mode amplitude approximation. When the deep-mode amplitude is plotted as a function of $\mathrm{SST}_{\text {rel }}$ and SC, it is clear that the new version of the two-mode model is preferable to the $\mathrm{BB} 09 \mathrm{~b}$ version (Fig. A2), so the new version is used subsequently. 
GPCP

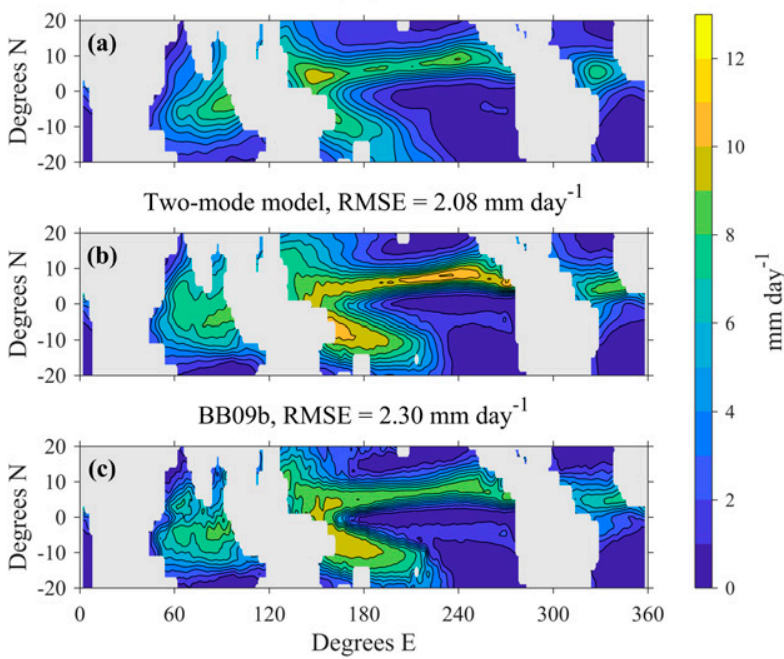

FIG. 1. Mean precipitation over August 1999 through July 2009 from (a) GPCP observations, (b) the two-mode model used here (smoothed), and (c) the two-mode model of BB09b (smoothed). Contour interval: $1 \mathrm{~mm}_{\text {day }^{-1}}$. Values of RMSE in (b) and (c) are of the climatological monthly precipitation relative to GPCP precipitation shown in (a), before smoothing.

\section{Precipitation response to climate change}

We apply the two-mode model to simulations of different climates from an ensemble of 20 coupled GCMs from CMIP5 (Taylor et al. 2012) listed in Table S1 in the online supplemental material. The response to climate change, denoted by $\Delta$, is defined as the difference between a historical and a warmer climate. The historical climate is the time mean of the historical simulation over 1980-99, and the warmer climate is the time mean of the RCP8.5 simulation over 2080-99, with some exceptions. ${ }^{3}$ For each GCM and for each of the historical and warmer climates, the vertical modes and parameters of the two-mode model are calculated using the GCM data for that climate following the approach described in the previous section. As shown in Fig. A1b, the vertical modes in the ensemble mean are similar to those obtained from reanalysis, and they shift upward with climate warming consistent with a general upward shift of the general circulation (Singh and O'Gorman 2012) and with a deepening of the maximum level of convection (Chou et al. 2013). Monthly precipitation from the twomode model is then calculated for each GCM and

\footnotetext{
${ }^{3}$ We use 1981-2000 for the historical period for GFDL-ESM2G, GFDL-ESM2M, and MRI-ESM1. We use 2081-2100 for the RCP8.5 period for GFDL-CM3, GFDL-ESM2G, GFDL-ESM2M, and MRI-ESM1. We use 2079-2098 for the RCP8.5 period for HadGEM2-ES.
}

climate using climatological monthly $\mathrm{SST}_{\mathrm{rel}}$ and $\mathrm{SC}$ from the GCMs as inputs. To give greater emphasis on the aspects that are common among models, we take the ensemble mean across GCMs prior to calculating RMS, RMSE, and $r^{2}$ values.

The two-mode model applied to the historical climate in the GCMs accurately reproduces the time- and ensemble-mean precipitation as simulated by the GCMs $\left(\right.$ RMSE $\left.=1.31 \mathrm{~mm} \mathrm{day}^{-1}\right)$. The two-mode model also accurately reproduces the changes in time-mean precipitation $(\Delta P)$ with climate warming both in the ensemble mean, as shown in Fig. 2, and in individual GCMs, as shown for the MPI-ESM-MR model in Fig. 3. We chose MPI-ESM-MR to show in Fig. 3 because it is an example of a model with a $\Delta P$ that is quite different from the ensemble mean. For MPI-ESM-MR, the strong precipitation increase in the western Pacific extends farther south, there is little change in the ITCZ region of the central Pacific, and the changes in the Indian and Atlantic basins are larger as compared to the ensemble mean. These differences between $\Delta P$ for MPI-ESM-MR and the ensemble mean are broadly captured by the twomode model.

To evaluate the contributions of wet get wetter, warmer get wetter, and changes in SC, we recalculate $\Delta P$ from the two-mode model allowing only the relevant terms in the expression for $\chi$ [Eq. (7)] to respond to climate change. In the framework of the DSE budget, the increase in DSE stratification, $-(\partial s / \partial p)$, with warming corresponds to a wet-get-wetter mechanism (Muller and O'Gorman 2011), and this increase dominates the changes in $M_{\text {ses }}$ and $M_{\text {sed }}$. Therefore, to evaluate the wet-get-wetter contribution, only $M_{\text {ses }}$ and $M_{\text {sed }}$ are allowed to respond to climate change in Eq. (7), while the mean of historical and RCP8.5 values are used for the other parameters and for SC and $\mathrm{SST}_{\text {rel. }}$. To evaluate the warmer-get-wetter contribution, only $\mathrm{SST}_{\text {rel }}$ is allowed to respond. To evaluate the contribution of $\Delta \mathrm{SC}$, only SC, which appears in both the shallowand deep-mode amplitudes, is allowed to respond. The sum of these three contributions to $\Delta P$ is not identically equal to the $\Delta P$ given by the two-mode model because of small changes in the parameters $\left(a_{s}, b_{\mathrm{SST}}, b_{\mathrm{SC}}, b_{0}\right.$, and $R_{0}$ ) and in the Heaviside function, but the sum of the three contributions is a good approximation to the total two-mode model response (RMSE of $0.20 \mathrm{~mm} \mathrm{day}^{-1}$ ).

The wet-get-wetter mechanism tends to increase the magnitude of precipitation where it is large in the historical climate (Figs. 2d and 3d). The warmer-get-wetter mechanism is primarily limited to part of the South Pacific where it contributes a strong negative precipitation change (Figs. 2e and 3e). Notably, much of the structure of $\Delta P$ is due to changes in SC, particularly in 

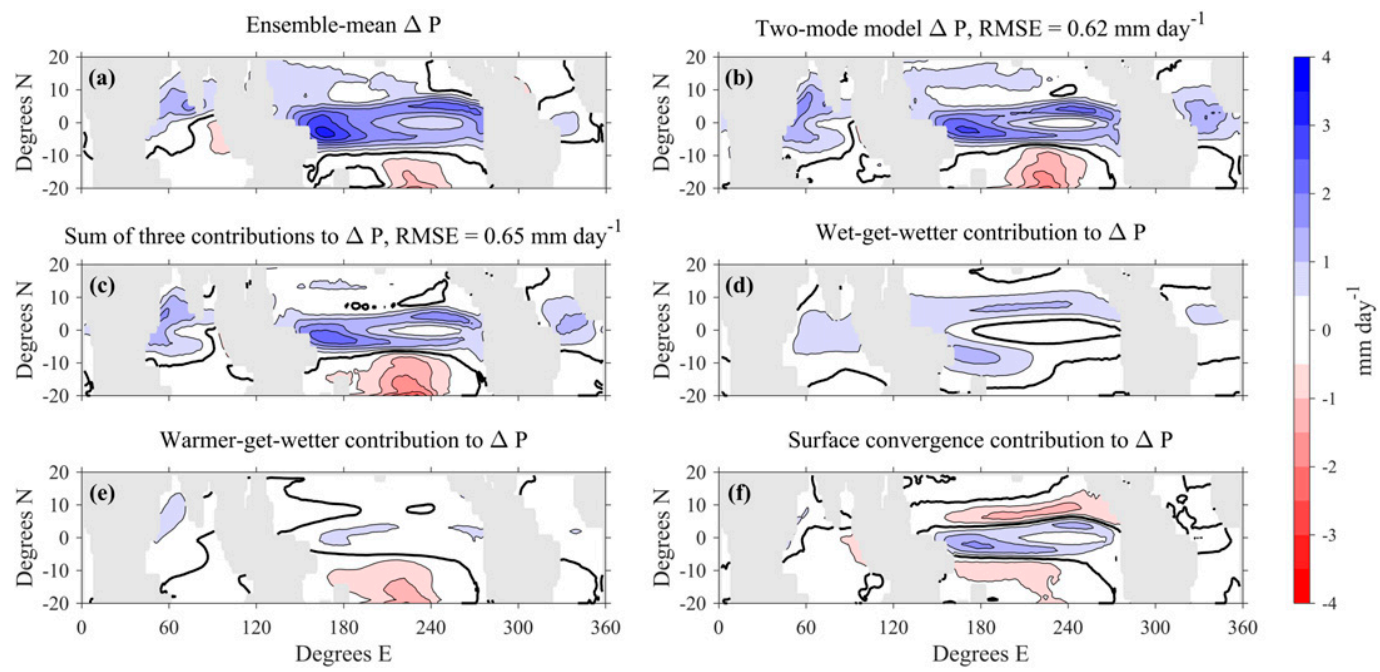

FIG. 2. Ensemble-mean response of precipitation to climate change (under RCP8.5) from (a) GCMs, (b) twomode model using parameters and modes calculated from each GCM and climate, (c) sum of contributions from wet get wetter, warmer get wetter, and changes in SC, (d) contribution from wet-get-wetter mechanism, (e) contribution from warmer-get-wetter mechanism, and (f) contribution from changes in SC. Contour interval: $0.5 \mathrm{~mm} \mathrm{day}^{-1}$. Zero contour denoted by thick black contour.

the Pacific in the ensemble mean (Fig. 2f) and in all basins for MPI-ESM-MR (Fig. 3f). A negative contribution from changes in SC partly offsets the positive wet-get-wetter contribution in some regions, but there are also regions where the SC contribution is positive. Overall, we find that the importance of the three contributions is relatively similar across models, but that they can combine to give different patterns of $\Delta P$. In the ensemble mean, the RMS values of the contributions are $0.53 \mathrm{~mm} \mathrm{day}^{-1}$ for wet get wetter, $0.40 \mathrm{~mm} \mathrm{day}^{-1}$ for warmer get wetter, and $0.63 \mathrm{~mm} \mathrm{day}^{-1}$ for SC.
The warmer-get-wetter and wet-get-wetter mechanisms have been discussed extensively in the literature. It is therefore notable that we find a strong contribution of changes in SC and a relatively limited contribution of warmer get wetter in our decomposition.

\section{Relationship between changes in $\mathrm{SC}$ and the Laplacian of low-level temperatures}

The importance of changes in SC in setting the precipitation response motivates us to better understand
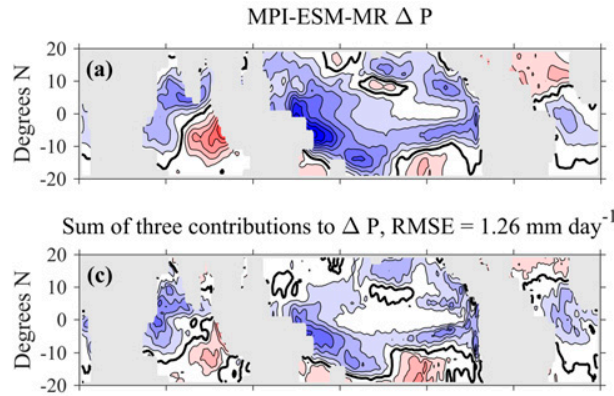

Warmer-get-wetter contribution to $\Delta \mathrm{P}$

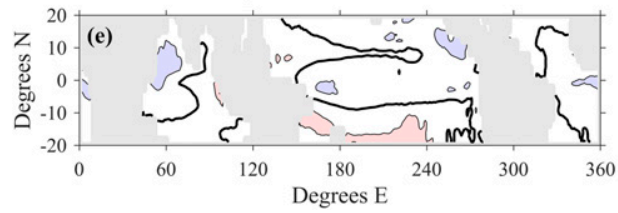

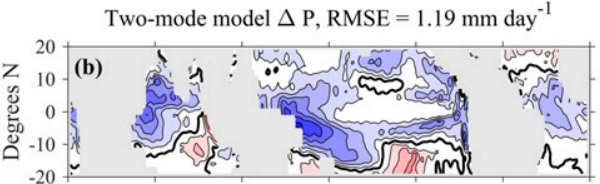

Wet-get-wetter contribution to $\Delta \mathrm{P}$

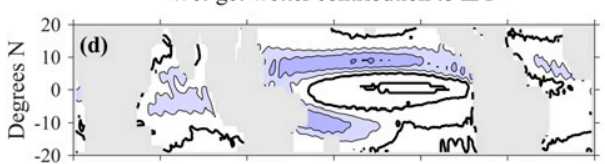

Surface convergence contribution to $\Delta \mathrm{P}$

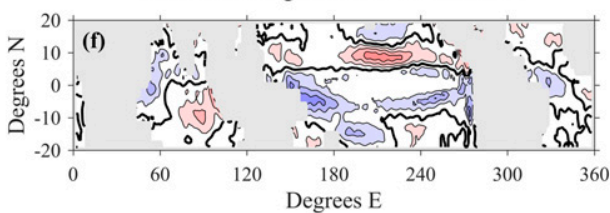

FIG. 3. As in Fig. 2, but for one GCM, MPI-ESM-MR, instead of the ensemble mean. 
what determines the pattern and magnitude of the changes in SC. The ensemble mean of the change in SC features a prominent increase in the equatorial Pacific flanked by bands of decreases farther south and north (Fig. 4a). Previous work suggests that low-level winds in the present climate are strongly affected by SST gradients. The SST gradients imprint on the boundary layer temperature gradients, which, by hydrostatic balance, induce horizontal pressure gradients that help to drive low-level winds (Lindzen and Nigam 1987; Battisti et al. 1999). In their simplest form, these arguments suggest that SC should be related to the curvature or Laplacian of SST (e.g., Sobel 2007). For climate change simulated by the CMIP5 models, we find that the pattern of change in SC is related to the spatially smoothed pattern of change in $\nabla^{2}$ SST $\left(\Delta \nabla^{2} S S T\right)$ with $r^{2}=0.39$ for the ensemble mean (Figs. 4a,b). By contrast, $\Delta \mathrm{SST}_{\text {rel }}$ is more strongly weighted to the Southern Hemisphere and is more weakly correlated with $\Delta \mathrm{SC}\left(r^{2}=0.26\right)$ and $\Delta \nabla^{2} \mathrm{SST}\left(r^{2}=0.21\right)$. The relatively high correlation of changes in SC with changes in $\nabla^{2} \mathrm{SST}$ suggests a possible role for convergence driven by boundary layer pressure gradients related to gradients of SST. We next use the MLM developed in Stevens et al. (2002) and BB09a to further investigate the relationship between changes in SC and changes in low-level temperatures.

The MLM is based on a horizontal momentum balance involving pressure gradients, Coriolis acceleration, surface drag, and downward momentum mixing from the free troposphere. According to the MLM, the bulk boundary layer zonal wind $U$ and meridional wind $V$ are given by

$$
\begin{gathered}
U \simeq \frac{U_{850} \varepsilon_{i} \varepsilon_{e}+V_{850} f \varepsilon_{e}-\rho_{0}^{-1}\left(f \frac{\partial p_{s}}{\partial y}+\varepsilon_{i} \frac{\partial p_{s}}{\partial x}\right)}{\varepsilon_{i}^{2}+f^{2}} \\
V \simeq \frac{V_{850} \varepsilon_{i} \varepsilon_{e}-U_{850} f \varepsilon_{e}+\rho_{0}^{-1}\left(f \frac{\partial p_{s}}{\partial x}-\varepsilon_{i} \frac{\partial p_{s}}{\partial y}\right)}{\varepsilon_{i}^{2}+f^{2}},
\end{gathered}
$$

where $U_{850}$ and $V_{850}$ are winds at $850 \mathrm{hPa}, \rho_{0}$ is a reference density set to $1.15 \mathrm{~kg} \mathrm{~m}^{-3}, f$ is the Coriolis parameter, $p_{s}$ is surface pressure, $\varepsilon_{e}$ is a tuned parameter related to entrainment mixing at the top of the boundary layer, and $\varepsilon_{i}$ is a tuned parameter related to both this entrainment mixing and surface friction. The fields $U_{850}$, $V_{850}$, and $p_{s}$ are taken from GCM output, with $p_{s}$ gradients spatially smoothed to reduce noise. For simplicity, we identify the convergence of the mixed layer winds in Eq. (8) with the convergence at the surface and refer to it as $\mathrm{SC}(\mathrm{MLM})$. Using the values for $\varepsilon_{e}$ and $\varepsilon_{i}$ from $\mathrm{BB} 09 \mathrm{a}$ results in $\mathrm{SC}$ that is too strong as compared to

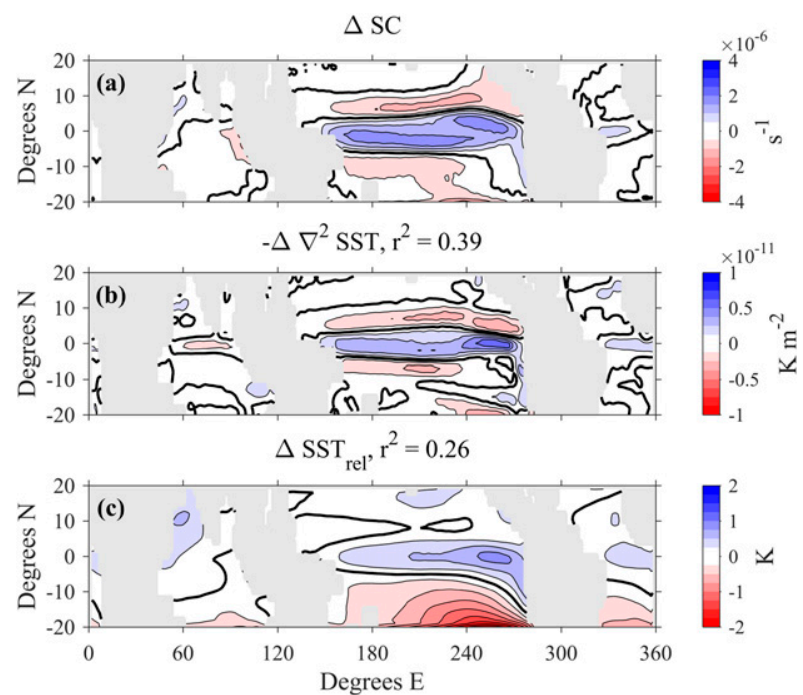

FIG. 4. Ensemble-mean response to climate change of (a) SC (contour interval: $5 \times 10^{-7} \mathrm{~s}^{-1}$ ), (b) negative of $\nabla^{2} \mathrm{SST}$ (smoothed, contour interval: $1.25 \times 10^{-12} \mathrm{~K} \mathrm{~m}^{-2}$ ), and (c) $\mathrm{SST}_{\text {rel }}$ (contour interval: $0.25 \mathrm{~K})$. Zero contour denoted by thick black contour. Values of $r^{2}$ in (b) and (c) are for monthly climatological values relative to the change in $\mathrm{SC}$ from the GCMs.

GCM SC for the historical climate. Doubling the value of the parameters $\varepsilon_{e}$ and $\varepsilon_{i}$ used by BB09a gives roughly the right magnitude of $\mathrm{SC}$ in the historical climate compared to the GCMs, so we set $\varepsilon_{e}=4 \times 10^{-5} \mathrm{~s}^{-1}$ and $\varepsilon_{i}=7 \times 10^{-5} \mathrm{~s}^{-1}$.

We compare SC(MLM) to the ensemble mean of SC from 11 of the CMIP5 GCMs, which we refer to as $\mathrm{SC}(\mathrm{GCM})$. The GCMs used are listed in the middle column of Table S1. ${ }^{4}$ In the historical climate, SC(MLM) is in reasonable agreement with $\mathrm{SC}(\mathrm{GCM})$ in pattern and magnitude (not shown). The pattern of $\triangle \mathrm{SC}(\mathrm{MLM})$ generally agrees with $\triangle \mathrm{SC}(\mathrm{GCM})$, but the magnitude of the dominant negative-positive-negative feature in the Pacific is generally weaker and narrower in $\triangle \mathrm{SC}(\mathrm{MLM})$ than in $\triangle \mathrm{SC}(\mathrm{GCM})$ (Figs. 5a,b).

We next derive two approximations for SC from the MLM: one that involves the Laplacian of boundary layer virtual temperature $\left[\operatorname{SC}\left(\nabla^{2} T_{v}\right)\right]$ and one that involves the Laplacian of SST $\left[\mathrm{SC}\left(\nabla^{2} \mathrm{SST}\right)\right]$.

\section{a. Approximation 1: $\mathrm{SC}\left(\nabla^{2} T_{v}\right)$}

The first approximation relates SC to horizontal temperature variations in the boundary layer. Following

\footnotetext{
${ }^{4}$ CMCC-CESM, CMCC-CM, CMCC-CMS, CSIRO-Mk3.6.0, and MPI-ESM-MR are excluded because surface specific humidity was not available for these models, and CanESM2, CNRM-CM5, MIROC5, and MIROC-ESM are excluded because of pronounced spectral ringing in the surface pressure field.
} 


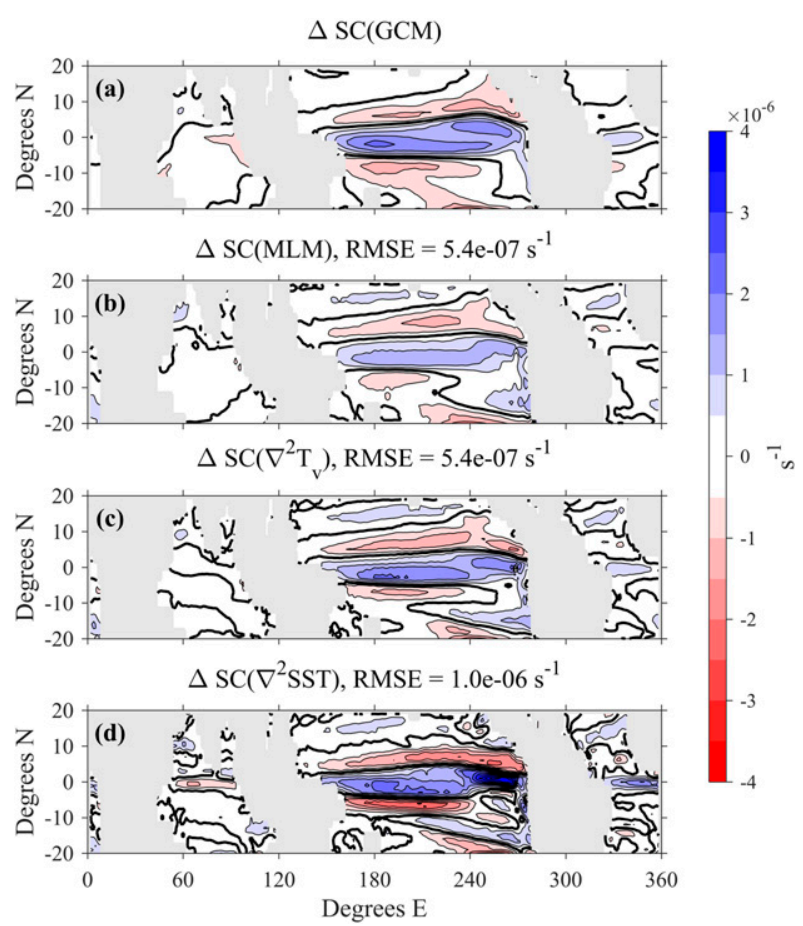

FIG. 5. Ensemble-mean response of SC to climate change from (a) GCMs, (b) MLM given by Eq. (8), (c) $\operatorname{SC}\left(\nabla^{2} T_{v}\right)$ given by Eq. (12), and (d) $\operatorname{SC}\left(\nabla^{2} \mathrm{SST}\right)$ given by Eq. (13). Contour interval: $5 \times 10^{-7} \mathrm{~s}^{-1}$. Zero contour denoted by thick black contour. The MLM and approximations are applied to each GCM and climate separately. The subset of models used for this figure is given in the middle column of Table S1.

$\mathrm{BB} 09 \mathrm{a}$, the boundary layer is assumed to include the surface to the top of the trade inversion. The nominal boundary layer top is located at the mean height of the $850-\mathrm{hPa}$ pressure surface, $\bar{z}_{850}$, and the local pressure at $z=\bar{z}_{850}$ is denoted $p_{i}$. Combining the hydrostatic relation and the ideal gas law yields

$$
p_{s}=p_{i} e^{\frac{g}{R_{d}} \int_{\mathrm{BL}} T_{v}^{-1} d z},
$$

where $R_{d}$ is the gas constant for dry air, $g$ is the acceleration due to gravity, $\int_{\mathrm{BL}} d z=\int_{0}^{\bar{z}_{850}} d z$ is an integral over the boundary layer, and $T_{v}$ is virtual temperature evaluated as $T_{v}=(1+0.61 q) T$ where $q$ is specific humidity.

BB09a showed that the contributions to SC from horizontal gradients of $p_{i}$ and downward mixing of the winds at $850 \mathrm{hPa}$ partly offset due to geostrophic balance at $\bar{z}_{850}$. The sum of these contributions to SC was found to be much smaller than the contribution from horizontal gradients in the pressure difference across the boundary layer. Therefore, we seek an approximation that neglects horizontal variations in $p_{i}$ and terms involving the winds at $850 \mathrm{hPa}$. Taking the horizontal gradient of Eq. (9), neglecting horizontal variations of $p_{i}$, and again making use of Eq. (9) gives that

$$
\begin{aligned}
& \frac{\partial p_{s}}{\partial x} \simeq-\frac{p_{s} g}{R_{d}} \int_{\mathrm{BL}} \frac{\partial T_{v}}{\partial x} \frac{d z}{T_{v}^{2}}, \\
& \frac{\partial p_{s}}{\partial y} \simeq-\frac{p_{s} g}{R_{d}} \int_{\mathrm{BL}} \frac{\partial T_{v}}{\partial y} \frac{d z}{T_{v}^{2}} .
\end{aligned}
$$

Substituting Eq. (10) in Eq. (8) and neglecting terms involving $U_{850}$ and $V_{850}$ gives an expression for SC in terms of horizontal gradients of boundary layer virtual temperature:

$$
\begin{aligned}
& \operatorname{SC}\left(T_{v}\right)=-\nabla \cdot \mathbf{V}\left(T_{v}\right), \quad \text { where } \\
& U\left(T_{v}\right) \simeq \frac{p_{s} g}{R_{d} \rho_{0}\left(\varepsilon_{i}^{2}+f^{2}\right)}\left(f \int_{\mathrm{BL}} \frac{\partial T_{v}}{\partial y} \frac{d z}{T_{v}^{2}}+\varepsilon_{i} \int_{\mathrm{BL}} \frac{\partial T_{v}}{\partial x} \frac{d z}{T_{v}^{2}}\right) \\
& V\left(T_{v}\right) \simeq-\frac{p_{s} g}{R_{d} \rho_{0}\left(\varepsilon_{i}^{2}+f^{2}\right)}\left(f \int_{\mathrm{BL}} \frac{\partial T_{v}}{\partial x} \frac{d z}{T_{v}^{2}}-\varepsilon_{i} \int_{\mathrm{BL}} \frac{\partial T_{v}}{\partial y} \frac{d z}{T_{v}^{2}}\right) .
\end{aligned}
$$

Explicit evaluation of the convergence of the winds in Eq. (11) shows that $\operatorname{SC}\left(T_{v}\right)$ includes a term involving the Laplacian of $T_{v}$ and that some of the other terms cancel each other. The Laplacian term is dominant, and the first approximation is simply that term, given by

$$
\mathrm{SC}\left(\nabla^{2} T_{v}\right) \simeq-\frac{p_{s} g \varepsilon_{i}}{R_{d} \rho_{0}\left(\varepsilon_{i}^{2}+f^{2}\right)} \int_{\mathrm{BL}} \frac{\nabla^{2} T_{v}}{T_{v}^{2}} d z,
$$

where $\nabla^{2} T_{v}$ is the Laplacian of virtual temperature. Lindzen and Nigam (1987) also found that the Laplacian term was important for SC, but they found that a beta convergence term related to variations in $f$ with latitude was of similar importance. The beta convergence term makes a much smaller contribution in our MLM formulation because we use a stronger frictional coefficient that is more similar to the ones used by Stevens et al. (2002) and Back and Bretherton (2009a).

In practice, we evaluate $\int_{\mathrm{BL}}$ in pressure coordinates by using the hydrostatic relation and approximating the upper limit as $850 \mathrm{hPa}$ rather than $p_{i}$. It is found that $\mathrm{SC}\left(\nabla^{2} T_{v}\right)$ accurately reproduces $\mathrm{SC}(\mathrm{MLM})$ in pattern and magnitude in the historical climate (not shown) and in the response to climate change (Figs. 5b,c).

\section{b. Approximation 2: $\mathrm{SC}\left(\nabla^{2} \mathrm{SST}\right)$}

We further approximate $\operatorname{SC}\left(\nabla^{2} T_{v}\right)$ [Eq. (12)] to get an expression for SC proportional to $\nabla^{2} S S T$. As noted by Lindzen and Nigam (1987), the horizontal pattern of temperature imprinted by the SST decays with height throughout the boundary layer. For simplicity, we assume that the temperature pattern decays linearly 
with height through the boundary layer as $\nabla^{2} T_{v} \simeq$ $\nabla^{2} \operatorname{SST}\left\{1-\left[z /\left(2 \bar{z}_{850}\right)\right]\right\}$. We approximate $T_{v}^{2} \simeq \mathrm{SST}^{2}$ in the denominator of Eq. (12), which is accurate to the extent that the temperature difference across the boundary layer is much smaller than the SST. Plugging these approximations into Eq. (12) gives

$$
\mathrm{SC}\left(\nabla^{2} \mathrm{SST}\right) \simeq-\frac{3 \bar{z}_{850} p_{s} g \varepsilon_{i}}{4 R_{d} \rho_{0}\left(\varepsilon_{i}^{2}+f^{2}\right) \mathrm{SST}^{2}} \nabla^{2} \mathrm{SST} .
$$

As compared to $\mathrm{SC}\left(\nabla^{2} T_{v}\right), \mathrm{SC}\left(\nabla^{2} \mathrm{SST}\right)$ reproduces much of the spatial pattern but is too strong in magnitude for both the historical climate (not shown) and the response to climate change (Figs. 5c,d). As compared to SC(GCM), $\operatorname{SC}\left(\nabla^{2} S S T\right)$ captures several of the main features of the response to climate change but also has substantial errors (Figs. 5a,d).

Overall, the results in this section show that the projected effect of climate change on SC over tropical oceans is largely driven by changes in the Laplacian of boundary layer temperatures, and the main features of the SC response are related to changes in the $\nabla^{2} \mathrm{SST}$. Given the widespread importance of the change in SC for the precipitation response, this suggests an important "Laplacian-of-warming" mechanism that acts alongside wet get wetter and warmer get wetter for the precipitation response over tropical oceans.

\section{Estimating precipitation response using approximations for SC}

We next examine the extent to which the two-mode model captures changes in precipitation when SC is approximated rather than taken from the GCMs. In particular, replacing SC(GCM) in the two-mode model with $\operatorname{SC}\left(\nabla^{2} T_{v}\right)$ or $\operatorname{SC}\left(\nabla^{2} S S T\right)$ gives a model for precipitation whose only spatially varying inputs are SST and boundary layer virtual temperatures [when $\operatorname{SC}\left(\nabla^{2} T_{v}\right)$ is used] or just SST [when $\operatorname{SC}\left(\nabla^{2} S S T\right.$ ] is used). Only the GCMs for which the MLM can be calculated are included in the analysis (Table S1), but this subset of GCMs gives similar results for the simulated $\Delta P$ and the two-mode model prediction for $\Delta P$ with $\mathrm{SC}(\mathrm{GCM})$ (Figs. 6a,b) as compared to the full set of GCMs (Figs. 2a,b). The regression coefficients in the multiple regression for the deep-mode amplitude $\left(b_{0}, b_{\mathrm{SST}}\right.$, and $\left.b_{\mathrm{SC}}\right)$ are recalculated for each of the approximations of SC.

When $\triangle \mathrm{SC}(\mathrm{MLM})$ is used instead of $\triangle \mathrm{SC}(\mathrm{GCM})$ to estimate $\Delta P$, the positive anomaly in the east Pacific weakens, which contributes to an increase in RMSE of $0.29 \mathrm{~mm} \mathrm{day}^{-1}$ (Figs. 6b,c). The approximations made to $\mathrm{SC}(\mathrm{MLM})$ to give $\mathrm{SC}\left(\nabla^{2} T_{v}\right)$ increase the RMSE of $\Delta P$ by only $0.05 \mathrm{~mm} \mathrm{day}^{-1}$ and the further approximations made to $\operatorname{SC}\left(\nabla^{2} T_{v}\right)$ to give $\operatorname{SC}\left(\nabla^{2} \mathrm{SST}\right)$ increase the RMSE of $\Delta P$ by $0.06 \mathrm{~mm} \mathrm{day}^{-1}$ (Figs. 6d,e). The main features of the ensemble-mean $\Delta P$ are qualitatively captured by all of the SC approximations: a positive anomaly in the northern part of the Indian Ocean; an elongated-C-shaped, positive anomaly in the Pacific Ocean; a negative anomaly in the South Pacific; and a small, positive anomaly in the Atlantic Ocean (Fig. 6). This is particularly notable for $\Delta P$ using the $\operatorname{SC}\left(\nabla^{2} \mathrm{SST}\right)$ approximation (Fig. 6e) since SST is the only spatially varying input.

However, errors in $\Delta P\left[\operatorname{SC}\left(\nabla^{2} \mathrm{SST}\right)\right]$ at each grid point are substantial enough that a more statistical model would not necessarily find that $\operatorname{SC}\left(\nabla^{2} \mathrm{SST}\right)$ strongly affects $\Delta P$. To illustrate this, consider the shallow mode, whose amplitude depends only on SC (or one of its approximations) through the coefficient $a_{s}$ in the twomode model [Eq. (5)]. We generally calculate $a_{s}$ from mass continuity, so it does not change as SC is approximated. However, in the version of the two-mode model with $\mathrm{SC}\left(\nabla^{2} \mathrm{SST}\right)$, if $a_{s}$ is calculated from a linear regression so that $a_{s}$ can change as SC is approximated, then the role of $\mathrm{SC}$ becomes muted and the precipitation response, including a faint elongated-C shape, is largely dominated by the wet-get-wetter and warmer-get-wetter mechanisms (cf. Figs. 6e,f). ${ }^{5}$ The fact that SC becomes muted when SC is approximated as $\mathrm{SC}\left(\nabla^{2} \mathrm{SST}\right)$ and $a_{s}$ is chosen by regression emphasizes that errors in $\operatorname{SC}\left(\nabla^{2} \mathrm{SST}\right)$ are important when using it to calculate the response of precipitation to climate change. The importance of errors in $\mathrm{SC}\left(\nabla^{2} \mathrm{SST}\right)$ can also be inferred from the decrease in the deep mode regression coefficient $b_{\mathrm{SC}}$ as SC is approximated. For example, in historical CMIP5 simulations, using $\operatorname{SC}\left(\nabla^{2} T_{v}\right)$ instead of SC decreases $b_{\mathrm{SC}}$ by nearly a factor of 2 , and using $\operatorname{SC}\left(\nabla^{2} \mathrm{SST}\right)$ instead of $\operatorname{SC}\left(\nabla^{2} T_{v}\right)$ reduces $b_{\mathrm{SC}}$ by a factor of 7 (Table S2).

\section{AMIP analysis}

The analyses in the previous sections suggest that changes in SC related to changes in the Laplacian of lowlevel warming are important for the response of precipitation to climate change. However, the simulations used involve changes in radiative absorbers and a sizable increase in mean temperature, which can also affect the

\footnotetext{
${ }^{5}$ When $\operatorname{SC}\left(\nabla^{2} \mathrm{SST}\right)$ is used, the structure of the wet-get-wetter mechanism differs from that shown in Fig. 2d because the shallowand deep-mode amplitudes are further approximated, and also because the subset of models used here gives a slightly different warmer-get-wetter pattern than that shown in Fig. 2e.
} 


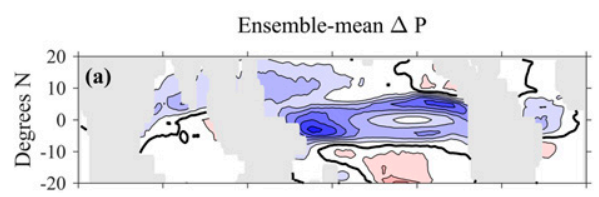

$\Delta \mathrm{P}[\mathrm{SC}(\mathrm{MLM})], \mathrm{RMSE}=0.96 \mathrm{~mm}$ day $^{-1}$

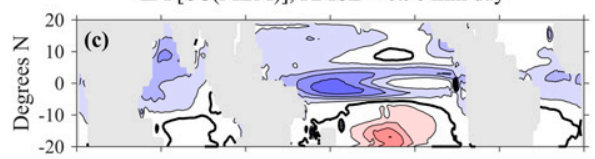

$\Delta \mathrm{P}\left[\mathrm{SC}\left(\nabla^{2} \mathrm{SST}\right)\right], \mathrm{RMSE}=1.07 \mathrm{~mm}^{\mathrm{day}}{ }^{-1}$

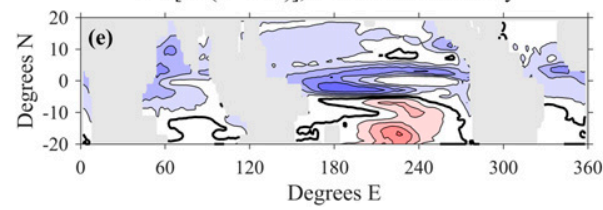

$\Delta \mathrm{P}[\mathrm{SC}(\mathrm{GCM})]\left(\right.$ two-mode model), $\mathrm{RMSE}=0.67 \mathrm{~mm}^{-1}{ }^{-1}$

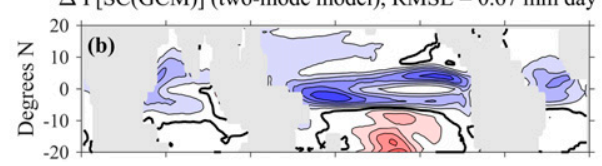

$\Delta \mathrm{P}\left[\mathrm{SC}\left(\nabla^{2} \mathrm{~T}_{\mathrm{v}}\right)\right], \mathrm{RMSE}=1.00 \mathrm{~mm}$ day $^{-1}$

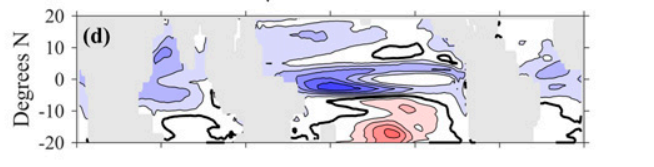

$\Delta \mathrm{P}\left[\mathrm{SC}\left(\nabla^{2} \mathrm{SST}\right)\right]$, shallow mode regression, $\mathrm{RMSE}=1.03 \mathrm{~mm}^{-1}{ }^{-1}$

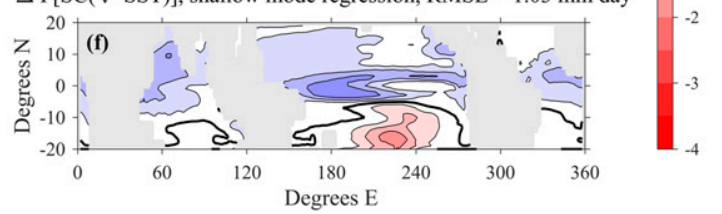

FIG. 6. Ensemble-mean response of precipitation to climate change from (a) GCMs, (b) the two-mode model, (c) the two-mode model with SC(MLM) as given by Eq. (8), (d) the two-mode model with $\mathrm{SC}\left(\nabla^{2} T_{v}\right)$ as given by Eq. (12), (e) the two-mode model with $\mathrm{SC}\left(\nabla^{2} \mathrm{SST}\right)$ as given by Eq. (13), and (f) the two-mode model with $\mathrm{SC}\left(\nabla^{2} \mathrm{SST}\right)$ and with the shallow-mode coefficient from a regression. The subset of models used for this figure is given in the middle column of Table S1. Contour interval: $0.5 \mathrm{~mm} \mathrm{day}^{-1}$. Zero contour denoted by thick black contour.

circulation and precipitation. Here, we further test our interpretation by using AMIP simulations to isolate the effects due to changes in the pattern of surface warming with climate change.

The AMIP simulations include a control simulation (AMIP_control), a simulation with a spatially uniform SST increase of $4 \mathrm{~K}$ (AMIP_4K), and a simulation with a spatially patterned SST increase (AMIP_future), of the years 1979 through 2008. The response to a "patternonly" change in SST (i.e., with no mean increase in SST) will be referred to as AMIP_pattern and is calculated as the normalized AMIP_future response minus the normalized AMIP_4K response. The response in each simulation is normalized by the change in tropical-mean SST, which differs slightly between simulations. This approach effectively assumes that the AGCM's responses are linear with surface warming. Seven AGCMs for which the necessary simulations and variables were available were used for the analysis (Table S1).

The two-mode model approximately reproduces $\Delta P$ for AMIP_pattern in the ensemble mean (Figs. 7a,b). Wet get wetter is negligible (Fig. 7d) because there is no mean warming and thus there is little change in the gross effective dry stratifications $M_{\text {ses }}$ and $M_{\text {sed }}$ whose changes we use to represent the wet-get-wetter mechanism. Absent wet get wetter, $\Delta P$ is dominated by the contributions from warmer get wetter (Fig. 7e) and $\Delta \mathrm{SC}$ (Fig. 7f), and the overall structure of $\Delta P$ is similar to that of the $\Delta \mathrm{SC}$ contribution. Further, we evaluate the contribution to the precipitation response from $\Delta \mathrm{SC}$ when it is replaced with each of the SC approximations: $\Delta \mathrm{SC}\left(\nabla^{2} T_{v}\right)$ and $\Delta \mathrm{SC}\left(\nabla^{2} \mathrm{SST}\right)$. As was done previously for Fig. 6, the regression coefficients in the multiple regression for the deep-mode amplitude $\left(b_{0}, b_{\mathrm{SST}}\right.$, and $\left.b_{\mathrm{SC}}\right)$ are recalculated for each of the approximations of SC. The contribution to $\Delta P$ from $\Delta \operatorname{SC}\left(\nabla^{2} T_{v}\right)$ has a weaker magnitude than the contribution from $\triangle \mathrm{SC}(\mathrm{GCM})$, but the pattern is similar (Fig. $7 \mathrm{~g}$ ). The contribution to $\Delta P$ from $\Delta \mathrm{SC}\left(\nabla^{2} \mathrm{SST}\right)$ has a similar pattern in the Pacific although there are differences over the Indian and Atlantic Oceans (Fig. 7h).

The two-mode model also approximately captures the precipitation response for both AMIP_4K and AMIP future (Figs. S1 and S2). The AMIP_4K response (Fig. S1) has a substantial wet-get-wetter contribution with no warmer-get-wetter contribution (because $\Delta \mathrm{SST}_{\text {rel }}$ is zero) and relatively weak changes in SC (consistent with zero imposed changes in the $\nabla^{2} \mathrm{SST}$ ). Differences between AMIP_4K $\Delta P$ and the wet-getwetter contribution do not resemble a weakening of the climatological precipitation pattern, and thus a weakening of the tropical divergent circulation due to spatial mean warming does not seem to be important for precipitation changes in our framework (see supplemental text for further discussion). The decomposition of the AMIP_future precipitation response (Fig. S2) is similar to what was discussed for the coupled models under RCP8.5. 

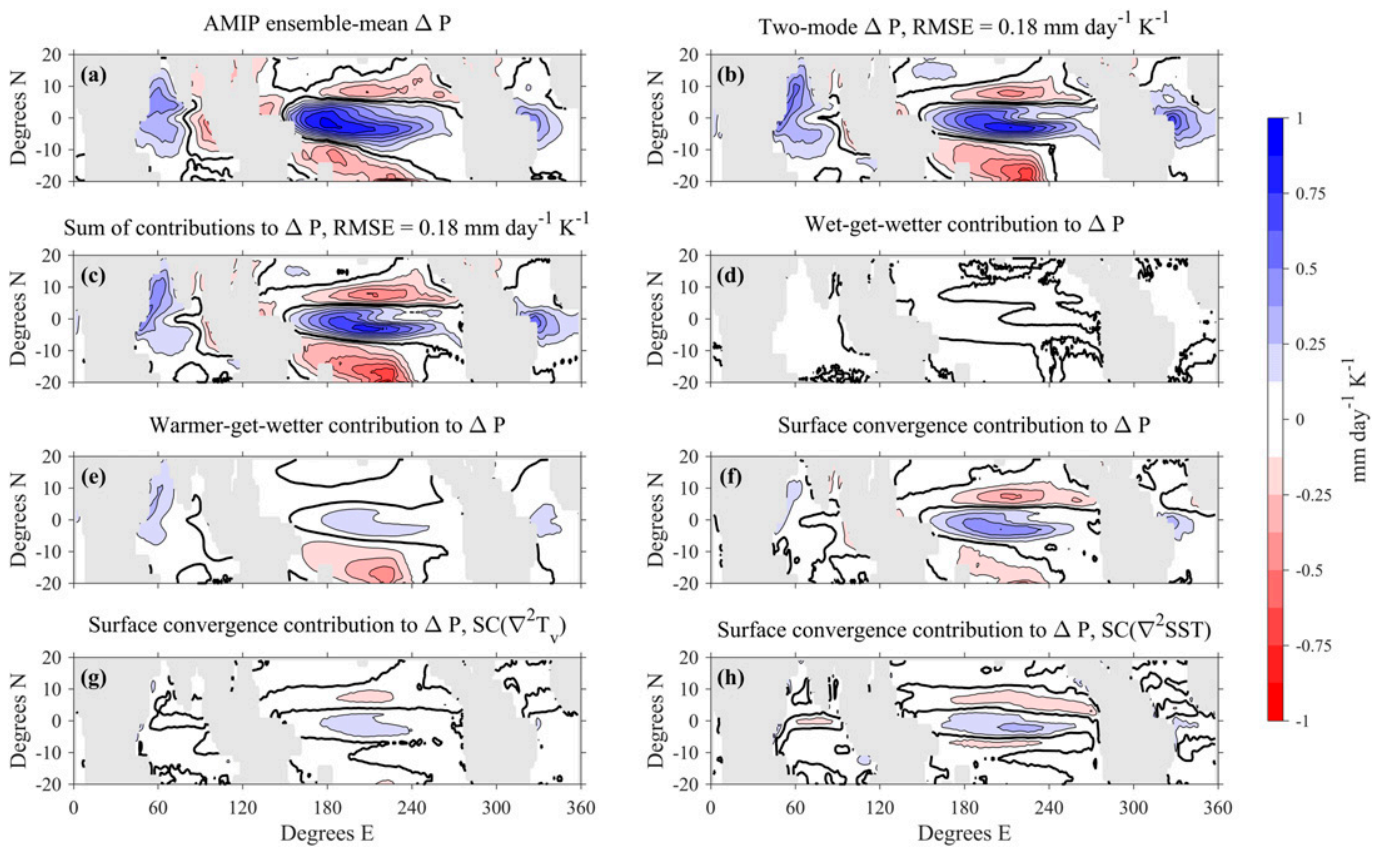

FIG. 7. Ensemble-mean response of precipitation to a pattern-only change in SST (AMIP_pattern): (a) AGCMs, (b) two-mode model, (c) sum of warmer-get-wetter, wet-get-wetter, and SC(GCM) contributions, (d) wetget-wetter contribution, (e) warmer-get-wetter contribution, (f) SC contribution based on SC(GCM), (g) SC contribution based on $\operatorname{SC}\left(\nabla^{2} T_{v}\right)$, and (h) SC contribution based on $\operatorname{SC}\left(\nabla^{2} \mathrm{SST}\right)$. The subset of models used is given in the right column of Table S1. The response is normalized by the change in tropical-mean SST. Contour interval: $0.125 \mathrm{~mm}_{\text {day }}{ }^{-1} \mathrm{~K}^{-1}$. Zero contour denoted by thick black contour.

Overall, the AMIP simulations support our interpretation of the contributions to changes in precipitation over tropical oceans: mean warming affects the precipitation response primarily via wet get wetter, while the pattern of changes in SST acts via warmer get wetter and a new "Laplacian-of-warming" mechanism.

\section{Conclusions}

We have analyzed precipitation projections from CMIP5 over the tropical oceans using a simple model for precipitation based on two modes of vertical motion. The need for two modes to describe vertical motion in the tropical atmosphere is well known based on analyses of the current climate, and here two modes are also used to analyze climate change. The two-mode model leads to a physical decomposition of the response of precipitation to climate change in which wet get wetter, warmer get wetter, and changes in SC are all needed to give the change in precipitation. Changes in $\mathrm{SC}$ and wet get wetter are of widespread importance, whereas warmer get wetter is primarily limited to the southern tropical Pacific. We went on to show using momentum balance in the boundary layer that the changes in $\mathrm{SC}$ can be approximated as proportional to changes in $\nabla^{2} T_{v}$ and, to a lesser extent, $\nabla^{2}$ SST. AMIP simulations were used to isolate the effect of the pattern of SST change versus the effect of the mean warming. The AMIP simulations were found to support our interpretation of an important role for changes in SC driven by changes in the Laplacian of low-level temperature.

Our results reveal that a "Laplacian-of-warming" mechanism is of widespread importance in precipitation projections in addition to the warmer-get-wetter and wet-get-wetter mechanisms. The Laplacian-of-warming mechanism may not have been distinguished from warmer get wetter previously because $\mathrm{SST}_{\text {rel }}$ and $\nabla^{2} \mathrm{SST}$ necessarily have some similarities in terms of spatial pattern and both can help to place precipitation maxima on SST maxima (cf. Sobel 2007). For example, Xie et al. (2010) found that the pattern of SST change was important for the response of precipitation, consistent with our results, but they attributed this to the dominant effect of changes in $\mathrm{SST}_{\text {rel }}$ on changes in gross moist stability. Our results show that changes in $\mathrm{SST}_{\mathrm{rel}}$ and changes in $\nabla^{2}$ SST nonetheless have quite different structure, particularly in terms of differences between the Northern and Southern Hemispheres (Figs. 4b,c), and we find correspondingly distinct contributions from warmer get wetter and Laplacian of warming. Ultimately, the fundamental difference between warmer 
get wetter and Laplacian of warming is between influences on precipitation that depend on SST changes relative to the tropical-average warming (through $\mathrm{SST}_{\text {rel }}$ ) and relative to the average warming in the immediate vicinity (through $\nabla^{2}$ SST).

One limitation of our results is that the errors in estimating changes in SC from $\nabla^{2}$ SST are substantial. Indeed, the role of $\operatorname{SC}\left(\nabla^{2} S S T\right)$ becomes muted if the constraint of mass continuity is neglected and all coefficients are chosen by regression (see Fig. 6f). In general, the accuracy is higher if boundary layer $\nabla^{2} T_{v}$ is used instead of $\nabla^{2}$ SST.

In addition to the climate model projections studied here, it would be interesting to apply the two-mode model to historical trends in precipitation and SSTs in climate model simulations and observations. We have not focused in particular on the ITCZ, but recent work suggests that $\nabla^{2}$ SST may be important in setting the width of the ITCZ consistent with our results (Byrne and Thomas 2019). Atmospheric energy balance, dictated in part by the ocean circulation and remote forcing, is thought to be important to ITCZ position (Kang et al. 2008; Schneider et al. 2014; Green and Marshall 2017), and using the two-mode model to address this would require coupling it to, for example, a mixed layer ocean rather than taking SST as given. Finally, we have focused exclusively on ocean regions, but a model of comparable simplicity to the two-mode model would also be useful for analysis of precipitation changes over tropical land.

Acknowledgments. We are grateful to three anonymous reviewers and to Tim Merlis and his group for feedback which led to improvements in the manuscript. This work is supported by NSF AGS 1552195.

Data availability statement: We acknowledge the World Climate Research Programme's Working Group on Coupled Modeling, which is responsible for CMIP, and Working Group on Numerical Experimentation, which is responsible for AMIP. We thank the climate modeling groups (listed in Table S1 of this paper) for producing and making available their model output. For CMIP the U.S. Department of Energy's Program for Climate Model Diagnosis and Intercomparison provides coordinating support and led development of software infrastructure in partnership with the Global Organization for Earth System Science Portals. NOAA OI SST V2 and GPCP data provided by the NOAA/OAR/ESRL PSD, Boulder, Colorado, USA, from their website at https://www.esrl.noaa.gov/psd/. QuikSCAT data were obtained from the NASA EOSDIS Physical Oceanography Distributed Active Archive Center at the Jet Propulsion Laboratory, Pasadena, CA.

\section{APPENDIX}

\section{Further Details of the Two-Mode Model}

Here we give additional details about the two-mode model and how it differs from the version of the model derived in BB09b.

Unlike BB09b, we use monthly climatological data throughout the paper, including for calculating the vertical motion profiles and as inputs to the two-mode model. Using monthly data rather than monthly climatological data would increase the RMSE values but would not affect our conclusions.

BB09b apply EOF analysis to convergence and integrate vertically to give modes in $\omega$ whereas we apply EOF analysis directly to $\omega$ for simplicity. The $\omega$ values are linearly interpolated to an evenly spaced pressure coordinate before the EOF analysis is applied, which eliminates the need for weighting by vertical grid spacing. The shallow and deep modes are linear combinations of these EOFs, chosen so that the shallow mode has zero near-surface convergence and the deep mode is orthogonal to the shallow mode. The shallow-mode structure is given by $\Omega_{s}=-\Omega_{1}+r \Omega_{2}$ and the deepmode structure is given by $\Omega_{d}=r \Omega_{1}+\Omega_{2}$, where $\Omega_{1}$ is the first EOF and $\Omega_{2}$ is the second EOF. The ratio $r$ is given by

$$
r=-\frac{\Omega_{2}(1000 \mathrm{hPa})-\Omega_{2}(950 \mathrm{hPa})}{\Omega_{1}(1000 \mathrm{hPa})-\Omega_{1}(950 \mathrm{hPa})},
$$

where 1000 and $950 \mathrm{hPa}$ are the two lowest pressure levels. The mode structures are then normalized to have unit length.

The structures of the original EOFs and of the shallow and deep modes from ERA-Interim are shown in Fig. A1a. In ERA-Interim, the first and second EOFs explain 89\% and $8 \%$ of vertical velocity variance, respectively, while the shallow-mode and deep-mode structures explain $70 \%$ and $27 \%$ of vertical velocity variance, respectively, with a total of $97 \%$ explained by the combination of the two modes. The ensemble-mean of the structures of the shallow and deep modes from the CMIP5 models are shown in Fig. A1b. The mode amplitudes, $o_{s}$ and $o_{d}$, determine the overall magnitude of the vertical velocity, and are positive in regions of high $\mathrm{SST}_{\text {rel }}$ and SC.

We also use a different approximation for the deepmode amplitude $o_{d}$ as compared to BB09b. BB09b argue that the deep-mode amplitude is related to SST using column stability arguments and the weak temperature gradient approximation aloft, and they approximated the deep-mode amplitude as $o_{d} \approx a \mathrm{SST}+b$, where $a$ and $b$ are regression coefficients. However, deep convection 

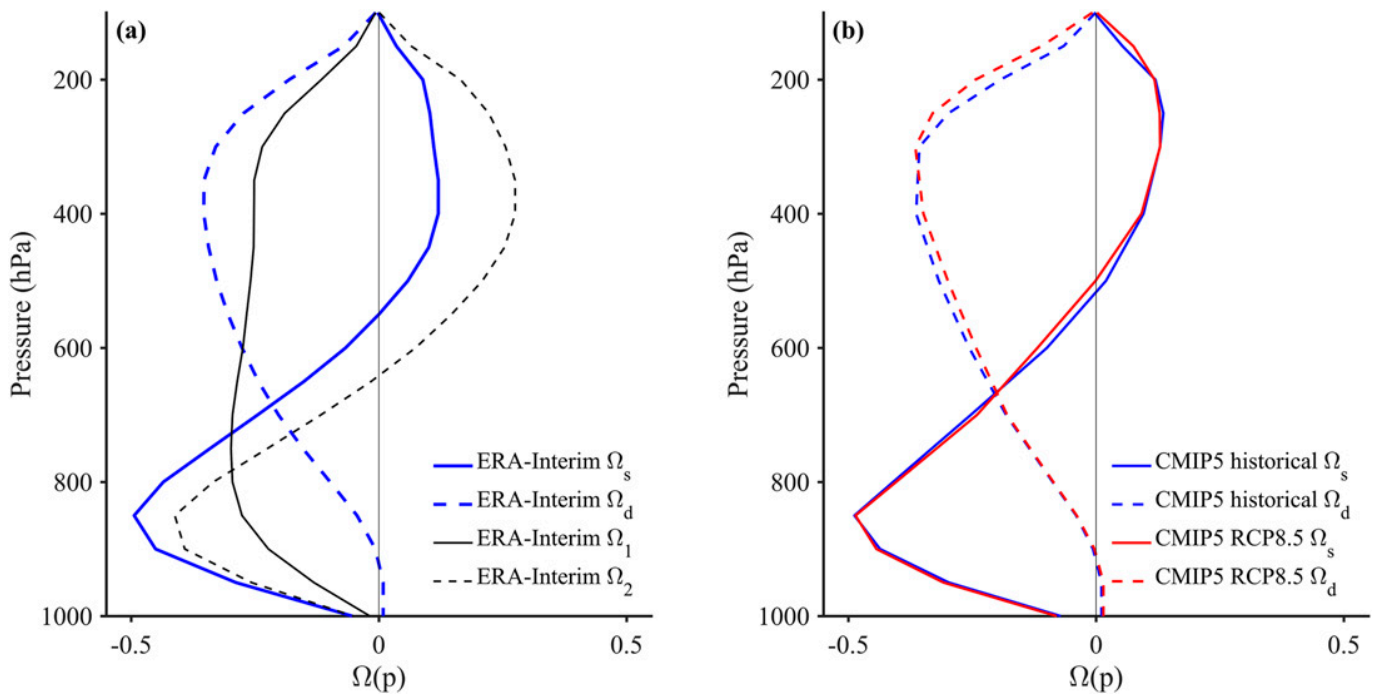

FIG. A1. Vertical velocity profiles for the shallow (solid) and deep (dashed) modes from (a) ERA-Interim and (b) the ensemble-mean historical climate (blue) and the ensemble-mean future climate under RCP8.5 (red). Thin black lines in (a) represent the unrotated modes from ERA-Interim. The amplitude is arbitrary.

is best supported when there is boundary layer convergence and lower-tropospheric moistening so that entrainment of dry air does not prevent deep convection. BB09b account for this by including a Heaviside function of SC in their precipitation model, effectively arguing that positive $\mathrm{SC}$ is a prerequisite for precipitation. The absence of precipitation for negative SC then implies a prediction for $o_{d}$ in order to close the DSE budget with no latent heating. The approximation used by BB09b for $o_{d}$ is calculated using SST from NOAA OI SST (Fig. A2c) and is compared to the deep-mode amplitude as calculated using ERA-Interim reanalysis
(Fig. A2a). Regions where a Heaviside function is invoked such that precipitation is zero are not contoured in Figs. A2b,c. The amplitudes are binned by SC and $\mathrm{SST}_{\text {rel }}$. More attention should be given to the region inside the white contour in which bins have 100 or more data points. The approximation used by BB09b does not capture the negatively sloped contours of constant $o_{d}$.

Here we instead approximate $o_{d}$ as a linear regression with $\mathrm{SST}_{\text {rel }}$ and SC as predictors [Eq. (6)]. The use of $\mathrm{SST}_{\text {rel }}$ in lieu of SST makes the model more consistent with the warmer-get-wetter mechanism, and thus more appropriate for application to climate change. The
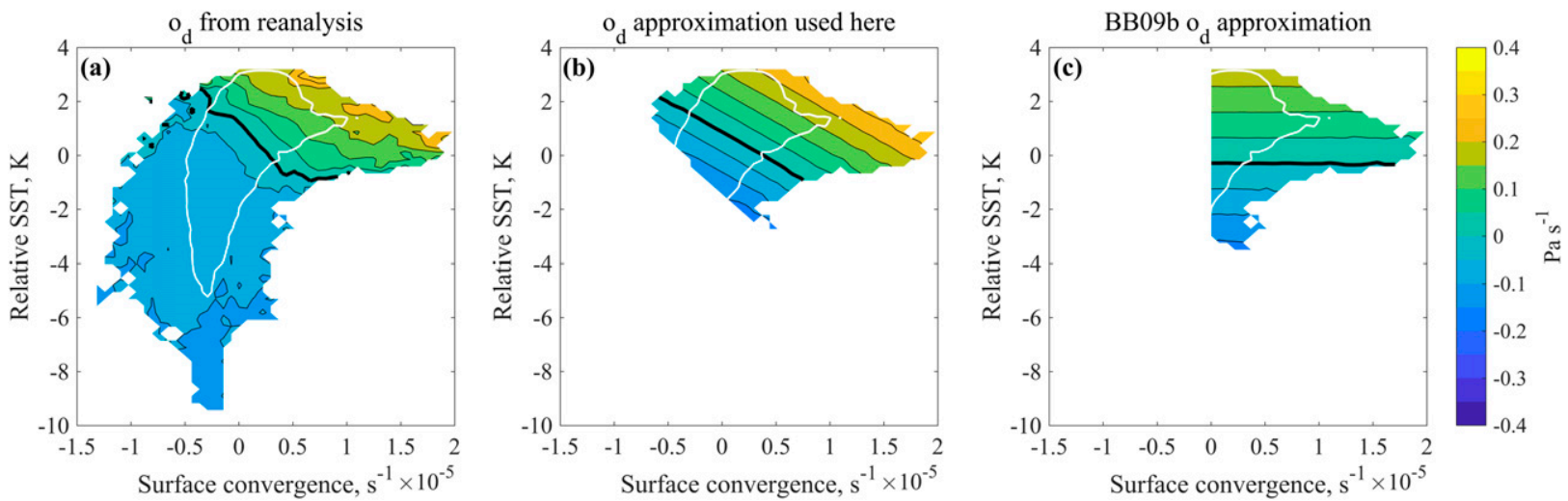

FIG. A2. Deep-mode amplitude $o_{d}$ calculated from climatological-mean monthly data over August 1999 through July 2009 and binned

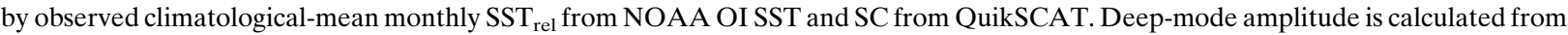
(a) ERA-Interim, (b) approximation used here [Eq. (6)] with $\mathrm{SST}_{\text {rel }}$ and SC as inputs, and (c) approximation used in BB09b (see appendix) with $\mathrm{SST}_{\mathrm{rel}}$ as input. Contour interval: $0.05 \mathrm{~Pa} \mathrm{~s}^{-1}$. White contour bounds bins with more than 100 data points per bin. Heavy black contour corresponds to deep-mode amplitude of zero. In (b) and (c), values of $o_{d}$ where a Heaviside function is invoked, resulting in zero precipitation, are not shown. 
inclusion of SC in the deep-mode regression means that the deep-mode amplitude increases with shallow-mode amplitude consistent with the role of shallow moistening in favoring deep ascent. This new approximation does not require the Heaviside of SC to be included in the precipitation expression, but there is still a Heaviside function to prevent negative precipitation. The deepmode amplitude approximated in this way agrees better with the deep-mode amplitude as calculated from reanalysis (Fig. A2). The setting of precipitation to exactly zero by a Heaviside function for certain SC and $\mathrm{SST}_{\text {rel }}$ values is a shortcoming of the $o_{d}$ approximations, but observed precipitation is light at those values (not shown).

Last, BB09b calculated their shallow-mode coefficient, $a_{s}$, using a linear regression whereas we calculate it using mass continuity, but similar values for $a_{s}$ emerge from both approaches.

Values for constants that appear in the two-mode model are given in Table S2.

\section{REFERENCES}

Adler, R. F., and Coauthors, 2003: The version-2 Global Precipitation Climatology Project (GPCP) monthly precipitation analysis (1979-present). J. Hydrometeor., 4, 1147-1167, https://oi.org/ 10.1175/1525-7541(2003)004<1147:TVGPCP $>2.0$. CO;2.

Back, L. E., and C. S. Bretherton, 2006: Geographic variability in the export of moist static energy and vertical motion profiles in the tropical Pacific. Geophys. Res. Lett., 33, L17810, https:// doi.org/10.1029/2006GL026672.

— boundary layer winds, and convergence over the tropical oceans. J. Climate, 22, 4182-4196, https://doi.org/10.1175/ 2009JCLI2392.1.

— and vertical motion patterns over the tropical oceans. J. Climate, 22, 6477-6497, https://doi.org/10.1175/2009JCLI2393.1.

_ Z Z. Hansen, and Z. Handlos, 2017: Estimating vertical motion profile top-heaviness: Reanalysis compared to satellite-based observations and stratiform rain fraction. J. Atmos. Sci., 74, 855-864, https://doi.org/10.1175/JAS-D-16-0062.1.

Battisti, D. S., E. S. Sarachik, and A. C. Hirst, 1999: A consistent model for the large-scale steady surface atmospheric circulation in the tropics. J. Climate, 12, 2956-2964, https://doi.org/ 10.1175/1520-0442(1999)012<2956:ACMFTL > 2.0.CO;2.

Bretherton, C. S., and D. L. Hartmann, 2009: Large-scale controls on cloudiness. Clouds in the Perturbed Climate System, J. Heintzenberg, and R. J. Charlson, Eds., MIT Press, 217-234.

Byrne, M. P., and P. A. O'Gorman, 2015: The response of precipitation minus evapotranspiration to climate warming: Why the wet-get-wetter, dry-get-drier scaling does not hold over land. J. Climate, 28, 8078-8092, https://doi.org/10.1175/JCLID-15-0369.1.

_ _ and R. Thomas, 2019: Dynamics of ITCZ width: Ekman processes, non-Ekman processes, and links to sea surface temperature. J. Atmos. Sci., 76, 2869-2884, https://doi.org/ 10.1175/JAS-D-19-0013.1.

Chadwick, R., I. Boutle, and G. Martin, 2013: Spatial patterns of precipitation change in CMIP5: Why the rich do not get richer in the tropics. J. Climate, 26, 3803-3822, https://doi.org/ 10.1175/JCLI-D-12-00543.1.

— , P. Good, G. Martin, and D. P. Rowell, 2016: Large rainfall changes consistently projected over substantial areas of tropical land. Nat. Climate Change, 6, 177-181, https://doi.org/ 10.1038/nclimate2805.

Chou, C., and J. D. Neelin, 2004: Mechanisms of global warming impacts on regional tropical precipitation. J. Climate, 17, 2688-2701, https://doi.org/10.1175/1520-0442(2004)017<2688: MOGWIO $>2.0 . \mathrm{CO} ; 2$.

,,-- C.-A. Chen, and J.-Y. Tu, 2009: Evaluating the rich-getricher mechanism in tropical precipitation change under global warming. J. Climate, 22, 1982-2005, https://doi.org/ 10.1175/2008JCLI2471.1.

_ T.-C. Wu, and P.-H. Tan, 2013: Changes in gross moist stability in the tropics under global warming. Climate Dyn., $\mathbf{4 1}$, 2481-2496, https://doi.org/10.1007/s00382-013-1703-2.

Collins, M., and Coauthors, 2013: Long-term climate change: Projections, commitments and irreversibility. Climate Change 2013: The Physical Science Basis, T. F. Stocker et al., Eds., Cambridge University Press, 1029-1136.

Dee, D. P., and Coauthors, 2011: The ERA-Interim reanalysis: Configuration and performance of the data assimilation system. Quart. J. Roy. Meteor. Soc., 137, 553-597, https://doi.org/ 10.1002/qj.828.

Green, B., and J. Marshall, 2017: Coupling of trade winds with ocean circulation damps ITCZ shifts. J. Climate, 30, 43954411, https://doi.org/10.1175/JCLI-D-16-0818.1.

Held, I. M., and B. J. Soden, 2006: Robust responses of the hydrological cycle to global warming. J. Climate, 19, 5686-5699, https://doi.org/10.1175/JCLI3990.1.

Huang, P., 2014: Regional response of annual-mean tropical rainfall to global warming. Atmos. Sci. Lett., 15, 103-109, https:// doi.org/10.1002/asl2.475.

_ , S.-P. Xie, K. Hu, G. Huang, and R. Huang, 2013: Patterns of the seasonal response of tropical rainfall to global warming. Nat. Geosci., 6, 357-361, https://doi.org/10.1038/ngeo1792.

Kang, S. M., D. M. Frierson, I. M. Held, and M. Zhao, 2008: The response to the ITCZ to extratropical thermal forcing: Idealized experiments with a GCM. J. Climate, 21, 3521-3532, https:// doi.org/10.1175/2007JCLI2146.1.

Kent, C., R. Chadwick, and D. P. Rowell, 2015: Understanding uncertainties in future projections of seasonal tropical precipitation. J. Climate, 28, 4390-4413, https://doi.org/10.1175/ JCLI-D-14-00613.1.

Knutti, R., and J. Sedláček, 2013: Robustness and uncertainties in the new CMIP5 climate model projections. Nat. Climate Change, 3, 369-373, https://doi.org/10.1038/nclimate1716.

Lindzen, R. S., and S. Nigam, 1987: On the role of sea surface temperature gradients in forcing low-level winds and convergence in the tropics. J. Atmos. Sci., 44, 2418-2436, https:// doi.org/10.1175/1520-0469(1987)044<2418:OTROSS $>$ 2.0.CO;2.

Ma, J., and S.-P. Xie, 2013: Regional patterns of sea surface temperature change: A source of uncertainty in future projections of precipitation and atmospheric circulation. J. Climate, 26, 2482-2501, https://doi.org/10.1175/JCLI-D-12-00283.1.

Muller, C. J., and P. A. O'Gorman, 2011: An energetic perspective on the regional response of precipitation to climate change. Nat. Climate Change, 1, 266-271, https://doi.org/10.1038/nclimate1169.

NASA, 2012a: Seawinds on QuikSCAT level 3 surface eastward wind for climate model comparison, version 1. PO.DAAC, accessed 6 September 2016, http://doi.org/10.5067/QSSEW-CMIP1. 
, 2012b: Seawinds on QuikSCAT level 3 surface northward wind for climate model comparison. version 1. PO.DAAC, accessed 6 September 2016, http://doi.org/10.5067/QSSNW-CMIP1.

Naumann, A. K., B. Stevens, and C. Hohenegger, 2019: A moist conceptual model for the boundary layer structure and radiatively driven shallow circulations in the trades. J. Atmos. Sci., 76, 1289-1306, https://doi.org/10.1175/JAS-D-18-0226.1.

Neelin, J. D., M. Münnich, H. Su, J. E. Meyerson, and C. E. Holloway, 2006: Tropical drying trends in global warming models and observations. Proc. Natl. Acad. Sci. USA, 103, 6110-6115, https://doi.org/10.1073/pnas.0601798103.

Peters, M. E., and C. S. Bretherton, 2005: A simplified model of the Walker circulation with an interactive ocean mixed layer and cloud-radiative feedbacks. J. Climate, 18, 4216-4234, https:// doi.org/10.1175/JCLI3534.1.

Reynolds, R. W., N. A. Rayner, T. M. Smith, D. C. Stokes, and W. Wang, 2002: An improved in situ and satellite SST analysis for climate. J. Climate, 15, 1609-1625, https://doi.org/10.1175/ 1520-0442(2002)015<1609:AIISAS > 2.0.CO;2.

Schneider, T., T. Bischoff, and G. H. Haug, 2014: Migrations and dynamics of the intertropical convergence zone. Nature, $\mathbf{5 1 3}$, 45-53, https://doi.org/10.1038/nature13636.

Seager, R., N. Naik, and G. A. Vecchi, 2010: Thermodynamic and dynamic mechanisms for large-scale changes in the hydrological cycle in response to global warming. J. Climate, 23, 4651-4668, https://doi.org/10.1175/2010JCLI3655.1.

Singh, M. S., and P. A. O'Gorman, 2012: Upward shift of the atmospheric general circulation under global warming: Theory and simulations. J. Climate, 25, 8259-8276, https://doi.org/ 10.1175/JCLI-D-11-00699.1.

Sobel, A. H., 2007: Simple models of ensemble-averaged precipitation and surface wind, given the sea surface temperature. The Global Circulation of the Atmosphere, T. Schneider and A. H. Sobel, Eds., Princeton University Press, 219-251.

- and D. J. Neelin, 2006: The boundary layer contribution to intertropical convergence zones in the quasi-equilibrium tropical circulation model framework. Theor. Comput. Fluid Dyn., 20, 323-350, https://doi.org/10.1007/s00162-0060033-y.

Stevens, B., J. Duan, J. C. McWilliams, M. Münnich, and J. D. Neelin, 2002: Entrainment, Rayleigh friction, and boundary layer winds over the tropical Pacific. J. Climate, 15, 3044, https://doi.org/10.1175/1520-0442(2002)015<0030: ERFABL $>2.0 . \mathrm{CO} ; 2$.

Taylor, K. E., R. J. Stouffer, and G. A. Meehl, 2012: An overview of CMIP5 and the experiment design. Bull. Amer. Meteor. Soc., 93, 485-498, https://doi.org/10.1175/BAMS-D-1100094.1.

Trenberth, K. E., D. P. Stepaniak, and J. M. Caron, 2000: The global monsoon as seen through the divergent atmospheric circulation. J. Climate, 13, 3969-3993, https://doi.org/10.1175/ 1520-0442(2000)013<3969:TGMAST>2.0.CO;2.

Xie, S.-P., C. Deser, G. A. Vecchi, J. Ma, H. Teng, and A. T. Wittenberg, 2010: Global warming pattern formation: Sea surface temperature and rainfall. J. Climate, 23, 966-986, https://doi.org/10.1175/2009JCLI3329.1. 